\title{
Status Report of Propagation Models: Middle East and North Africa (S5.3)
}

\author{
C.A. Schultz \\ H.J. Patton \\ P. Goldstein
}

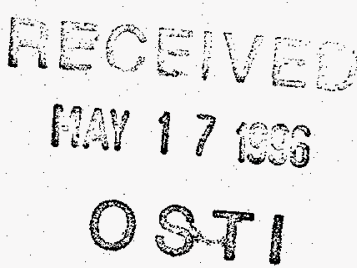

November 1995

This is an informal report intended primarily for internal or limited external distribution. The opinions and conclusions stated are those of the author and may or may not be those of the Laboratory.

Work performed under the auspices of the U.S. Department of Energy by the Lawrence Livermore National Laboratory under Contract W-7405-ENG-48. 


\section{DISCL AIMER}

This document was prepared as an account of work sponsored by an agency of the United States Government. Neither the United States Government nor the University of California nor any of their employees, makes any warranty, express or implied, or assumes any legal liability or responsibility for the accuracy, completeness, or usefulness of any information, apparatus, product, or process disclosed, or represents that its use would not infringe privately owned rights. Reference herein to any specific commercial product, process, or service by trade name, trademark, manufacturer, or otherwise, does not necessarily constitute or imply its endorsement, recommendation, or favoring by the United States Government or the University of California. The views and opinions of authors expressed herein do not necessarily state or reflect those of the United States. Government or the University of California, and shall not be used for advertising or product endorsement purposes.

This report has been reproduced directly from the best available copy.

Available to DOE and DOE contractors from the Office of Scientific and Technical Information

P.O. Box 62, Oak Ridge, TN 37831

Prices available from (615) 576-8401, FTS 626-8401

Available to the public from the

National Technical Information Service

U.S. Department of Commerce

5285 Port Royal Rd.

Springfield, VA 22161 


\section{DISCLATMER}

Portions of this doeument may be illegible in electronic image preduet Images are produced from the best available original document: 


\title{
Deliverable 21 - 8/15/95: ST482B FY95
}

Status Report of Propagation Models:

Middle East and North Africa (S5.3)

\author{
Craig A. Schultz, Howard J. Patton, Peter Goldstein \\ - Earth Sciences Division, Lawrence Livermore National Laboratory \\ University of California \\ Sponsored by DOE CTBT R\&D Program
}

\section{Introduction}

Portability of regional discriminants to complex tectonic regions

An improved understanding of the influence that tectonic structure has on regional seismic phases is needed to improve the current performance of regional discriminants and their transportability to the Middle East and North Africa. In the case that the crustal structure can be approximated by a flat layered laterally invariant medium, layer-cake reflectivity modeling can be used to obtain an accurate representation of regional phases. However, a laterally heterogeneous crust is just as common as a layered cake structure and in this case large variations in regional phase amplitudes are not uncommon. For instance, it has been shown that rough surface topography and undulations in the Moho can cause the transfer of energy between various surface wave modes and between surface waves and body waves greatly increasing the potential variability of seismic phases (Kennett, 1984; Bostock and Kennett, 1990; Gupta et al., 1992). Larger scale structure such as thickening or thinning of the crust can also greatly affect phase propagation. In some instances, changes between different tectonic regions such as that which occurs at a continental-oceanic boundary can completely block phases such as $\mathrm{Lg}$ (Kennett and Mykkeltveit, 1984; Kennett, 1986; Regan, 1987) rendering certain discriminants useless. In addition to structure along the path, lateral structure and free surface topography near the source and receiver can cause complex scattering effects with strong directional, frequency, and near-field effects (App et al., 1995; Johnson, 1995; McLaughlin, 1994). Given that the Middle East and North Africa cross many different tectonic boundaries, we are using numerical propagation models to understand how the relevant tectonic features affect the propagation of primary discriminant phases. 


\section{Modeling Tectonic Boundaries in the Middle East and North Africa}

As part of our effort to characterize the propagation of regional discriminant phases in the Middle East and North Africa, we have been making and assembling empirical observations on regional phase propagation in this region. At the same time, we have numerous external contractors gathering regional data in these regions. Parallel to this effort of characterizing regional seismic data we are developing correlations between structure and seismograms. This effort is through a collaboration with U.C. Santa Cruz to do statistical analyses of the sensitivity of various regional phases to specific crustal parameters in the western United States. Crustal parameters here include lateral heterogeneity such as variability in topography, basin thickness, crustal thickness, etc. LLNL is currently developing preliminary crustal and sediment thickness maps for the Middle East and North Africa for the purpose of calibrating these correlations in the region.

Combining the seismic data and structural databases gathered here at LLNL and the initial data acquired from our external contractors we have started modeling the response of discriminant phases to regions of complex structure in the Middle East and North Africa.

\section{Propagation across the Mediterranean Sea}

Preliminary results from the above work include an initial determination of regions where the seismic response can be explained with simple layered models and those regions which will require more general modeling of complex structures to explain the response. For instance, the Mediterranean region is one gateway through which to monitor North Africa from Europe. Unfortunately, this region does not respond as one would expect based on a standard layered crust model.

Figure 1 shows the propagation path for one event that occurred near Cairo and was recorded at ANTO in Turkey. Accessing the Cornell database to obtain the crustal profile along this propagation path (Figure 2 ) there are clearly strong fluctuations in both the Moho and Basement thickness in the Mediterranean area. In addition, a water body is encountered along the part of the path. Figure 3 shows the real data recorded at approximately $1200 \mathrm{~km}$ distance. This is compared with a reflectivity model using the best average plane layered structure in the region. The reflectivity solution predicts that much of the energy will arrive early in the seismogram, while clearly the data shows a strong delay of energy with a much more uniform amplitude as a function of time and a longer overall duration. It is apparent that we need to look more carefully at the response of the complex structure in this region to properly identify phase arrivals and to determine how the spectral content of each phase is affected. 
To predict the response of basin and Moho structure in this region, we utilize the most promising of our numerical techniques, ELAS3D. This is our 2D/3D finitedifference code optimized for regional wave propagation through complex structures. Figure 3 compares a finite-difference synthetic with the data recorded at ANTO. In this case there is a much closer match when we include the thick basin of sediments present beneath the Mediterranean Sea. These sediments act not only to delay much of the guided energy in the crust, but are also responsible for the significant increase in the duration of the seismogram. Figure 4 demonstrates just how unrealistic the plane layered model is for this region by comparing the reflectivity results to the finite difference results at various distances along the propagation path. One can see the great complexity added to the seismogram once energy encounters the Mediterranean Sea. The dramatic improvement in the fit between the finite-difference model and the real data suggests that modeling can be used to better predict the arrival time of discriminant phases and help understand the spectral distortion of each phase.

\section{Blockages in the Middle East}

Initial data collected in the Middle East shows that some features can greatly disrupt and in some cases totally block energy, potentially having a strong effect on discriminants. Based on our preliminary analysis, the Caspian Sea is one structure which may have a dramatic affect on guided crustal phases. To identify the extent of phase disruption and blockage by the Caspian structure, we look at data recorded at two stations in the Caspian network, KAT and LNK, which sit on opposite sides of the Caspian Sea as shown in Figure 1. Figure 5a shows the seismograms recorded at these two stations given an event along the Pacific Rim. Energy arrives first at the Eastern side of the Caspian Sea (KAT) with a well developed longperiod Rayleigh wavetrain. The effect of propagation through the Caspian structure can be observed by looking at the station LNK. Comparing this seismogram with KAT it is apparent that the Rayleigh wavetrain has been almost completely removed from the seismogram. Figure $5 \mathrm{~b}$ shows a similar blockage of Rayleigh energy for an event approaching from the west and passing through the Caspian Sea. As a result of this dramatic blockage of seismic energy, we are placing a large effort into better understanding the response of the various discriminant phases to these structures.

\section{Significance for Seismic Discrimination}

The ability to model the variability of phase amplitudes as the direct result of structure is important because these phases form the basis for detecting, locating, and identifying small magnitude events. Given the strong azimuthal variation in the structure of the Middle East and North Africa there will likely be significant variations in spectral amplitudes at a single station as a function of the back-azimuth and 
source-receiver distance. Our preliminary results show that these structures tend to affect each of the phases differently, potentially introducing large variability into discriminants which compare different phases, such as the Pn/Lg spectral ratios. We feel that numerical modeling will play an important role in the analysis of special events occurring in regions of low seismicity because it should enable us to determine whether the local structural response could cause enough discriminant variability to either mask a clandestine nuclear explosion or generate a false alarm.

\section{Acknowledgments}

Alan Ryall provided significant help in gathering the seismic data and obtaining the crustal model from the Cornell database. Stan Ruppert, Shawn Larsen, and Dave Harris all have helped to develop the numerical modeling capabilities utilized in this report. Research performed under the auspices of the U.S. Department of Energy by the Lawrence Livermore National Laboratory under contract W-7405ENG-48.

\section{References}

App, F.N., R.J. Bos, T.N. Dey, E.M. Jones, J.R. Kamm, \& S.R. Taylor, 1995, Examining near-source effects in the far field, 17th Seismic Research Symposium on Monitoring a CTBT, 609-616.

Bostock. M.G. and B.L.N. Kennett, 1990, The effect of 3-D structure on Lg propagation patterns, Geophys. J. Int., 101, 355-365.

Gupta, I.N., W.W. Chan, \& R.A. Wagner, 1992, A comparison of regional phases from underground nuclear explosions at east Kasakh and Nevada test sites, Bull. Seism. Soc. Am., 82, 352-382.

Johnson, L.R., 1995, The effect of near-receiver scattering on seismograms, 17th Seismic Research Symposium on Monitoring a CTBT, 421-432.

Kennett, B.L.N., 1984, Guided wave propagation in laterally varying media, I, theoretical development, Geophys. J, R. Astr. Soc., 79, 235-255.

Kennett. B.L.N., 1986, Lg waves and structural boundaries, Bull. Seism. Soc. Am., 76, 1133-1141.

Kennett. B.L.N., \& S. Mykkeltveit, 1984, Guided wave propagation in laterally varying media.II, Lg-waves in north-western Europe, Geophys. J. R. Astr. Soc., 79, 257-267.

McLaughlin, K.L., T.J. Barker, \& J.L. Stevens, 1994, Numerical simulation of quarry blast sources, Report\# SSS-FR-94-14418.

Regan, J., 1987, Numerical studies of propagation of Lg waves across ocean continent boundaries using the representation theorem, Ph.D. Thesis, California Institute of Technology, Pasadena, California. 


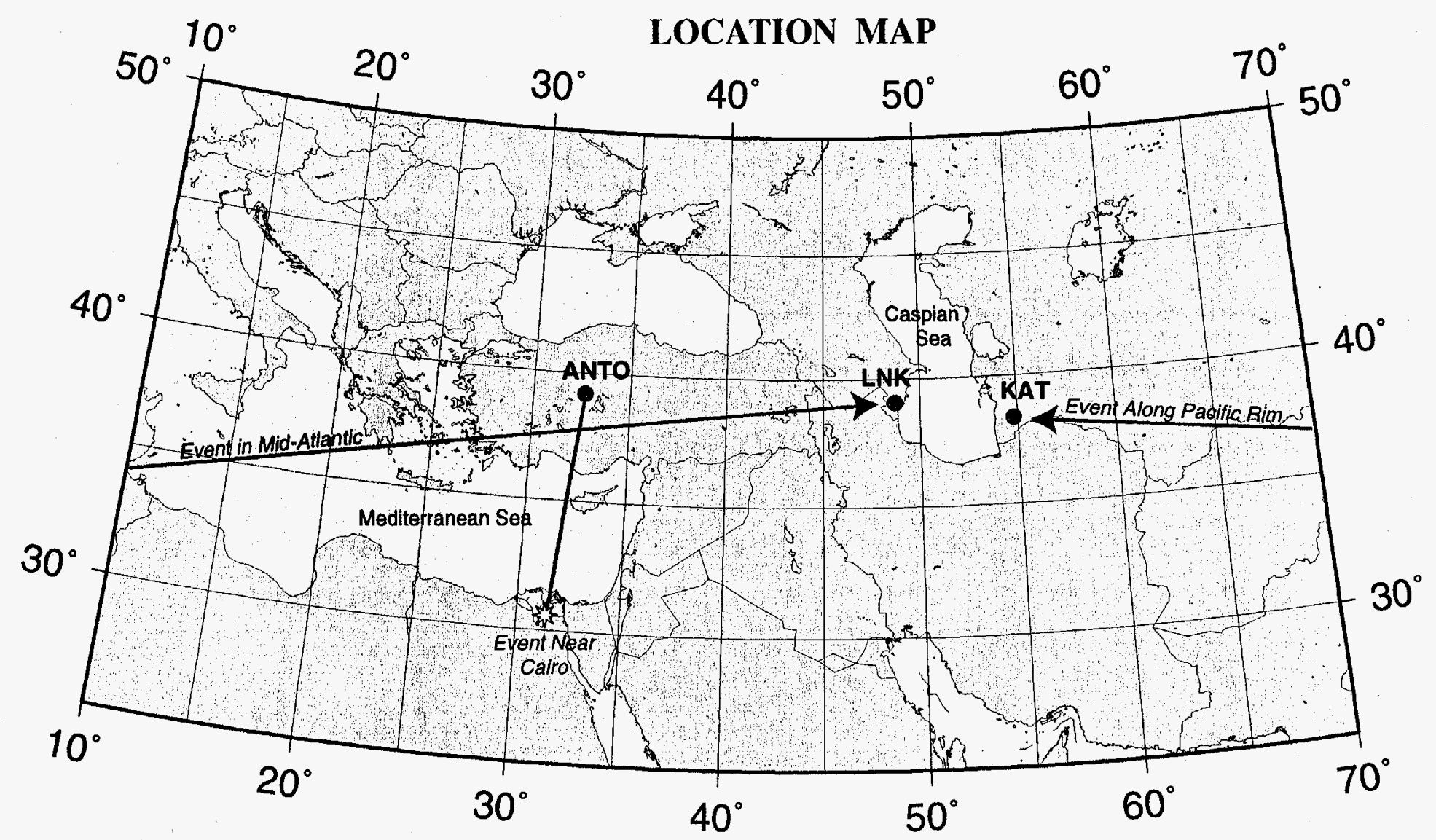

Figure 1: Location map showing the path of propagation (red line) for an event which occurred near Cairo and was recorded at ANTO in Turkey. This path crosses the Mediterranean Sea region. Two other events, one in the Atlantic Ocean and one in the Pacific Ocean are used to study blockage in the Caspian region. The approaching direction of energy propagating through the Caspian region is specified. 


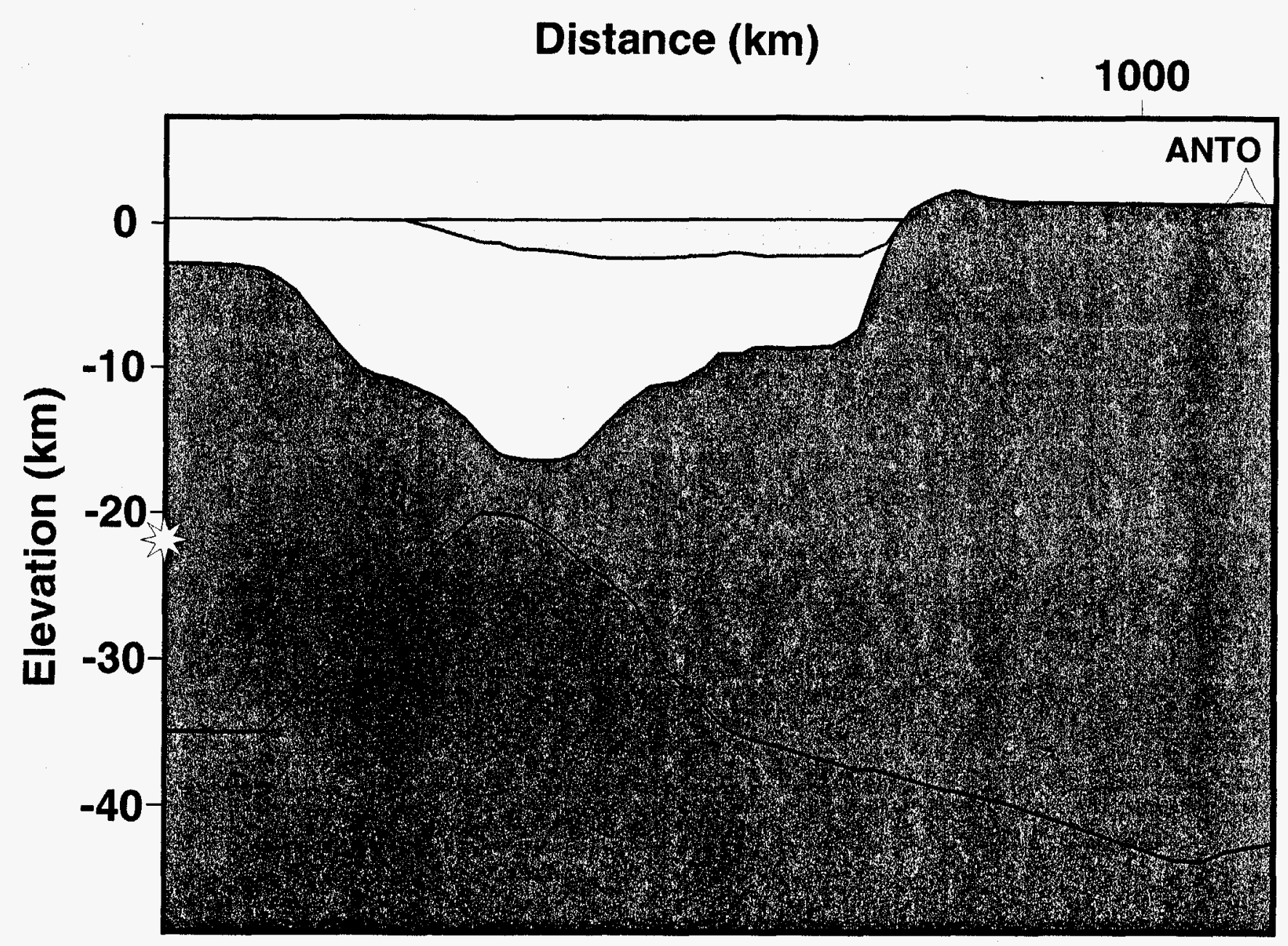

Figure 2: Crustal structure along the path from Cairo to ANTO. In the Mediterranean Sea region energy passes through an area of significant crustal thinning and sediment thickening. 


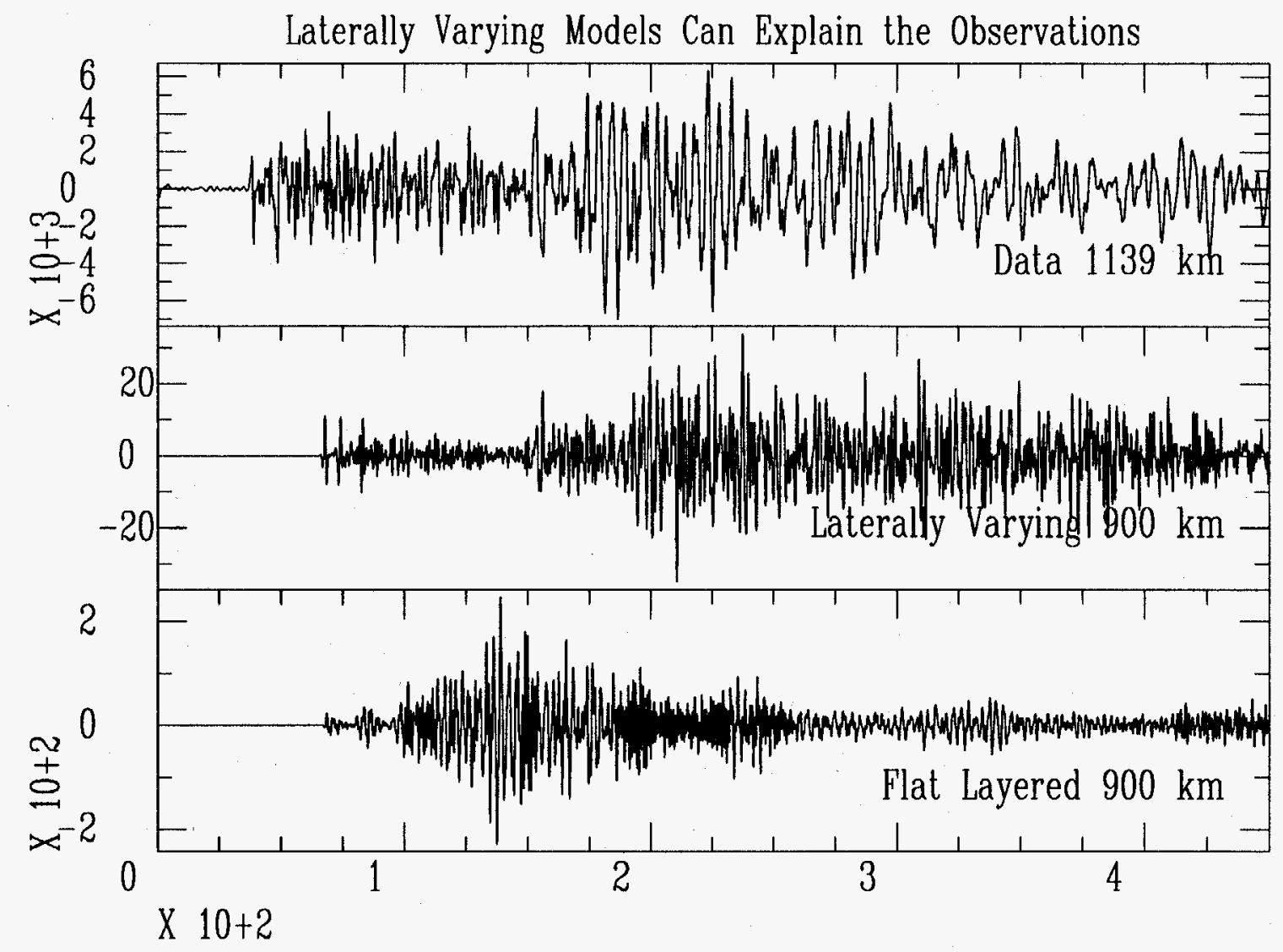

Time (sec)

Figure 3: Comparison of the vertical component seismogram observed at ANTO with the results of reflectivity and finite-difference modeling. Reflectivity modeling corresponds to an average plane layered, 1-D, structure for the propagation path while the finite-difference modeling includes the significant structural complexity near the Mediterranean Sea. 


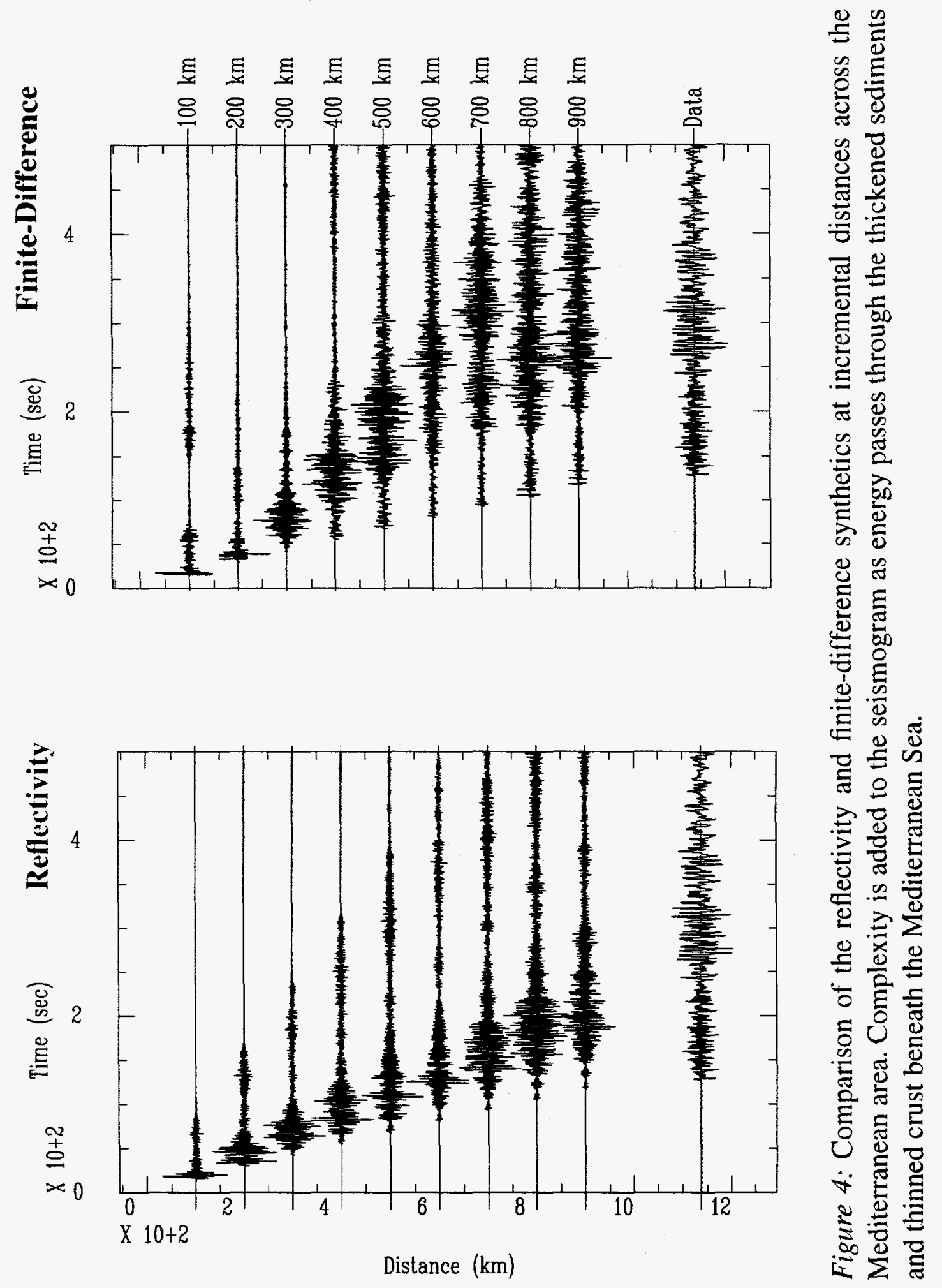


(a) Blockage of Rayleigh Waves Observed in the Caspian Sea Region

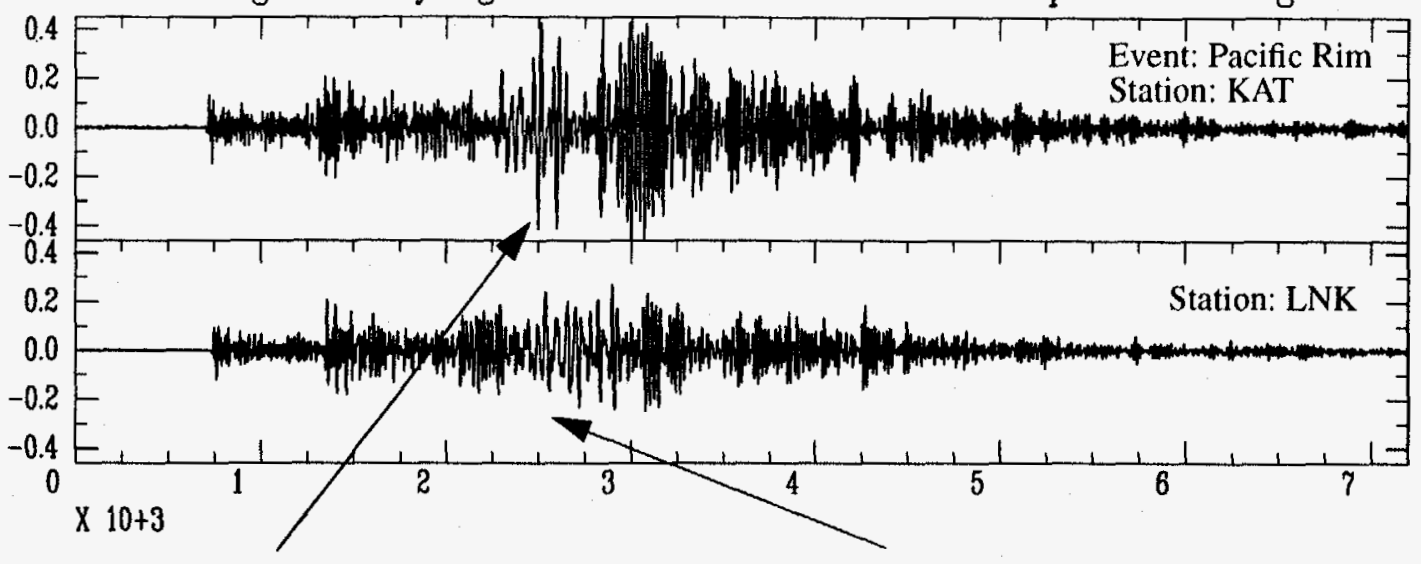

Rayleigh Wave Energy Strong

(b)

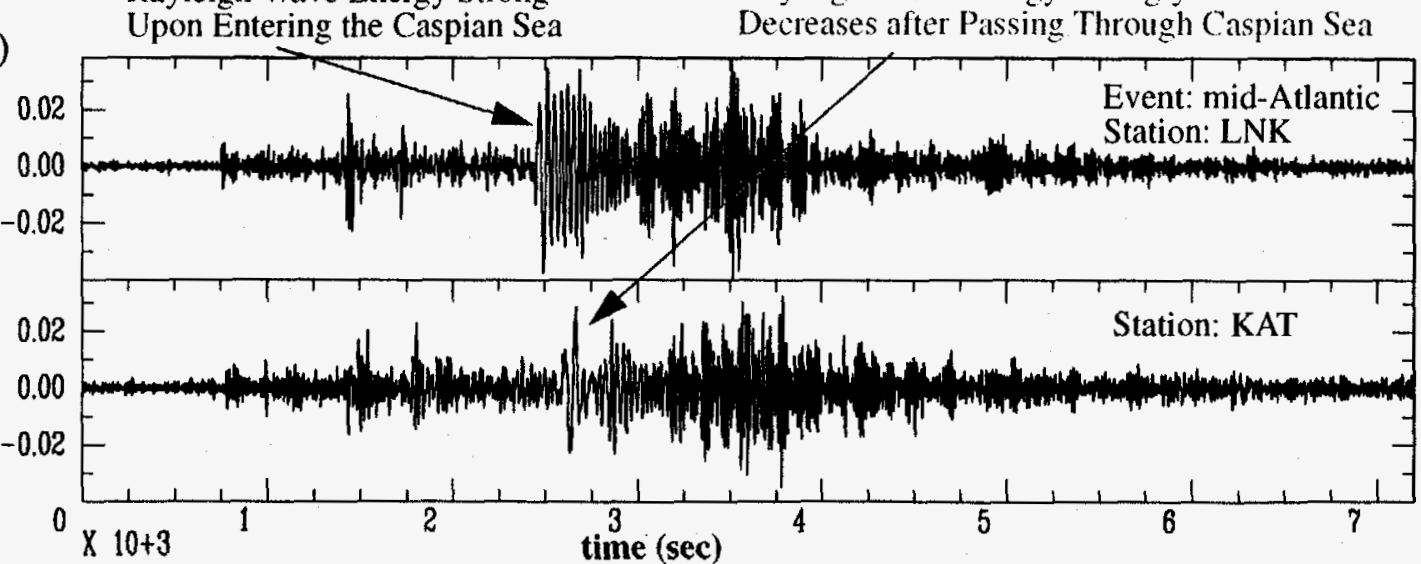

Figure 5: Comparison of vertical component seismograms for two events. One event (a) is located along the Pacific-Rim and and the other (b) is located in the mid-Atlantic. The two stations shown sit on opposite sides of the Caspian Sea (see Figure 1). 